\title{
Use of Boron Compounds as Binders in Iron Ore Pelletization
}

\author{
Osman Sivrikaya* and Ali Ihsan Arol
}

Middle East Technical University, Department of Mining Engineering, 06531 Çankaya, Ankara, Turkey

\begin{abstract}
Low grade iron ores with impurity gangue minerals containing silica and alumina must be upgraded to an acceptable level of iron content. Concentrates, due to their fine sizes, are not suitable to be directly charged to the iron-making processes such as the blast furnace or the DR-plant. Hence, an agglomeration technique should be applied to fine concentrate. The most commonly employed one is pelletizing in iron ore industry. In pelletizing, iron ore, water and a binder are balled in a mechanical disc or drum to produce agglomerates. Bentonite is the most widely used binder. However, it is considered as an impurity due to its high $\mathrm{SiO}_{2}$ and $\mathrm{Al}_{2} \mathrm{O}_{3}$ content. Many researchers have investigated different binders, mostly of organic origin, in pursuit of finding a viable alternative binder to bentonite. Organic binders were found to yield good quality green and dry pellets. However, they fail to impart enough strength to the pre-heated and fired pellets as a result of insufficient slag bonding. Boron compounds free of silica and alumina are thought to be a potential solution to overcome the lack of slag forming constituents encountered with organic binders as they are known for their low melting temperatures as well as for their ability to also lower the melting temperatures of silicates. A few researchers have investigated the use of boron compounds in iron ore agglomeration and found promising results which have been covered in this paper.
\end{abstract}

Keywords: Iron ore, Pelletization, Agglomeration, Bentonite, Organic binders, Boron compounds, Colemanite.

\section{IRON ORE PELLETIZING}

The main raw material in iron-steel industry is iron ore. Iron ores can be classified as high grade and low grade in terms of their $\mathrm{Fe}$ content. High grade iron ores which can be used directly in the blast furnace to produce metallic iron are not abundant in earth's crust to supply the need of iron-steel industry. The exploitation of low grade iron ores is possible after enrichment. Low grade iron ores contain a considerable amount of gangue minerals, e.g. silica, alumina, calcium and magnesium compounds, which require concentration. In concentration, iron ore is crushed and ground for liberation before the implementation of separation techniques. Liberation can mostly be achieved at a very fine particle size and, hence, the concentrate obtained is not suitable to be charged directly into the blast furnace or the DR-plant without converting it into suitably sized agglomerates. The most commonly employed agglomeration technique is pelletizing. In pelletizing, a mixture of iron ore, water and binder is rolled in a mechanical disc or drum to produce agglomerates (green balls or wet pellets). Green pellets then undergo a thermal process, which consists of three stages, namely drying (250 $\left.400^{\circ} \mathrm{C}\right)$, preheating $\left(900-1100^{\circ} \mathrm{C}\right)$ and firing $\left(1200-1300^{\circ} \mathrm{C}\right)$. Pellets are produced from magnetite concentrates, hematite concentrates, natural ore fines, artificial magnetites and pyrite cinders. Binder plays an important role in the success of pelletizing process. Of many binders, bentonite has proven to be the most effective one owing to its high water

*Address correspondence to this author at the Middle East Technical University, Department of Mining Engineering, 06531 Çankaya, Ankara, Turkey; Tel: +90 31221026 73; Fax +90 31221058 22:

E-mail': sivrikay@metu.edu.tr or osmansivrikaya@gmail.com adsorption capacity and dry film strength. It is used at a rate of $0.5-1.5 \%$. Bentonite, useful as explained, is however considered as an impurity due to its high $\mathrm{SiO}_{2}$ and $\mathrm{Al}_{2} \mathrm{O}_{3}$ contents. These acid oxides are known for their adverse effects on the iron-steel making economy. For instance, the addition of $1 \%$ bentonite decreases the iron content by about $7 \mathrm{~kg} / \mathrm{ton}$ of iron ore [1]. In addition, an increase in the gangue content of the charge leads to an increase in the unit cost of steel production [2]. In view of the adverse affects of bentonite, many researchers attempted to find viable alternative binders. Organic binders have attracted attention as they are known to have good binding properties. The results showed that organic binders produce good quality green and dry pellets. However, they fail to impart enough strength to the pre-heated and fired pellets as a result of reduced slag bonding [1,3-7], which is especially more important in pelletizing of hematite ores due to lack of oxide bonding. As such, organic binders have hitherto failed to be an alternative to bentonite, except a few cases of straight-grate pelletizing, where there is no dynamic pellet bed. In recent years efforts have been focused on improving the pre-heated and fired strength of pellets produced with organic binders. In this context, boron compounds have been considered as an additive in conjunction with organic binders.

\section{DESIRABLE PROPERTIES OF PELLETS}

Pellets should have certain quality parameters, which are mostly ascertained by the tests specified in international standards, e.g. ISO, ASTM, JIS etc. The important ones as follows.

\subsection{Size of Pellets}

At least $90 \%$ of pellets should be between $9.0 \mathrm{~mm}$ and $16 \mathrm{~mm}$ with minus $5 \mathrm{~mm}$ material of no more than $5 \%$. A 
close size distribution is preferred for a better permeability of the pellet bed in the induration machine.

\subsection{Strength of Pellet}

The strength of a pellet is dependent on the type of bonds produced by the binder as well as the phase changes during induration, as shown Fig. (1). A certain minimum compressive strength is necessary so that the pellets can withstand the compression load during transportation, drying grate, induration machine or in a reduction furnace [8].

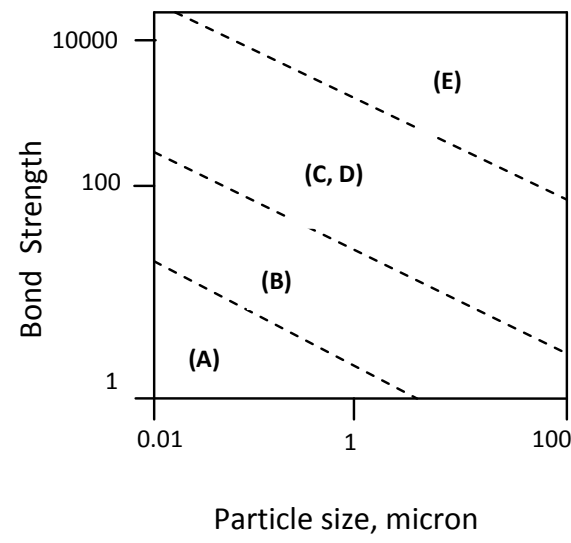

Fig. (1). Magnitudes of bond strength for various classes of interparticle bonds in pellets: (A) van der Waals', magnetic or electrostatic forces; (B) capillary forces from liquid phase; (C) adhesional and cohesional forces; (D) mechanical interlocking; (E) solid bridges formed by sintering or crystallization of dissolved materials [9].

Five different types of pellet strength are important in pelletization:

\subsubsection{Drop Number}

Repeated drop of 9-16 mm green pellets onto a steel plate from a height of $46 \mathrm{~cm}$ without any cracks on the green balls, measures the ability of the wet pellets to retain their shape during transfer operations. A pellet should withstand at least 4 drops, which also depends on the number of transfer points between the balling equipment and the induration machine.

\subsubsection{Wet Compressive Strength}

Green balls on conveyor belts and grates should withstand a certain load. Wet compressive strength is a measure of how much load a pellet can bear and determined by applying a certain load onto a pellet until it cracks. It should ideally be greater than $1.0 \mathrm{~kg} /$ pellet.

\subsubsection{Dry Compressive Strength}

In travelling grate a minimum dry pellet strength is necessary so that the pellets withstand the load of layers located above or the pressure of gases flowing through the charge [8]. A dried pellet is crushed and the maximum load is recorded. It measures the ability of dried pellets to survive handling during the firing process. Should be a mean value at least $2.24 \mathrm{~kg} / \mathrm{pellet}[10]$.

\subsubsection{Pre-Heated Pellet Strength}

Especially, when pellets are produced with the grate-kilncooler technology, they are pre-heated in the travelling grate prior to firing in the kiln. The pre-heated pellets from the grate are discharged by cascading into the kiln. Therefore, such pellets should be strong enough not to disintegrate during cascading and tumbling in the rotary kiln. In the case of weak pellets, dust and chips generated as a result of disintegration will cause losses in plant efficiency, in terms of both productivity and quality.

\subsubsection{Fired Compressive Strength}

Fired (indurated) pellet is crushed and the maximum load is recorded. It measures the ability of product pellets to survive handling during shipment and reduction. Pellets should have a mean product pellet compressive strength value of minimum $250 \mathrm{~kg} /$ pellet with the $<150 \mathrm{~kg} /$ pellet fraction less than $5 \%$.

\subsection{Tumble and Abrasion Indices}

Tumbling and abrasion procedure consists of subjecting product pellets $(-18+6.3 \mathrm{~mm})$ to 200 revolutions at 25 $\mathrm{rev} / \mathrm{min}$ in a drum. The Tumble Index (TI) is given by the percentage weight of $+6.3 \mathrm{~mm}$ material surviving the test, and Abrasion index (AI) by the percentage of $-0.5 \mathrm{~mm}$ material produced. Product pellets should have a TI of $92-97 \%$ and an AI of $2.5-5.0 \%$ [11].

\subsection{Porosity}

Porosity of typical wet and dry pellets is in the range of $31-36 \%$ whilst it should be $18-32 \%$ for fired pellets.

\subsection{Reducibility}

Reducibility is the degree of ease with which oxygen can be removed from pellet composition. In standard the product pellets is heated to $900^{\circ} \mathrm{C}$ under nitrogen and then the reducing test gas is passed through the pellets at the required flow rate. There are some reducibility tests and typical reducibility test results for product pellets are [11]:

- Linder test index : about $50 \%$

- Gakushin test : about $60 \%$ reduction

- Chiba test : reducibility index of $2.5-3.0 \mathrm{~mm} /$ hour

- V.D.E. test : rate of reduction of $0.6-1.0 \%$ / minute when the pellet is $60 \%$ oxidized

\subsection{Swelling}

Pellets tend to swell during reduction; swelling should not exceed $20 \%$ by volume for a smoother operation.

\section{BINDERS IN IRON ORE PELLETIZING}

Numerous types of materials have been considered for use as binders in iron ore pelletizing, with an objective of finding the material that would produce the highest-quality pellets at the lowest possible cost. . Binders that have been used can be broadly classified as follows;

- Clays and colloid minerals,

- Organic polymers and fibers,

- Cement and cementations materials,

- Salts and precipitates,

- Inorganic polymers [9]. 


\subsection{Function of Binders}

Binders are used to improve pellet properties as listed below:

- Promoting and facilitating - balling of iron ores in pelletizing drum or disc;

- The improvement of green, dry, pre-heated and fired pellet strength;

- Overcoming the problems associated with balls sensitive to heat in the drying stage, i.e. increase in shock temperature of green balls;

- Enabling the production of good quality pellets to be attained at lower temperatures;

- Improving the properties of the fired pellets [9].

During the development of the pelletizing process, a great number of organic and inorganic substances were tested with regard to their suitability as binders.

\subsection{Bentonite: The Conventional Binder}

Bentonite, a mixture of clay mineral, consists of montmorillonite as the major component and small quantities of quartz, mica, feldspar and kaoline. The basic crystal structure of montmorillonite is shown in Fig. (2) and it has a lattice structure arranged in layers which is capable of absorbing great water quantities between the individual layers. On such occasions the distances between the lattice layers increase considerably. The mineral swells. This swelling property and the high thixotropic behavior are the most important characteristics for its bonding capacity [8].

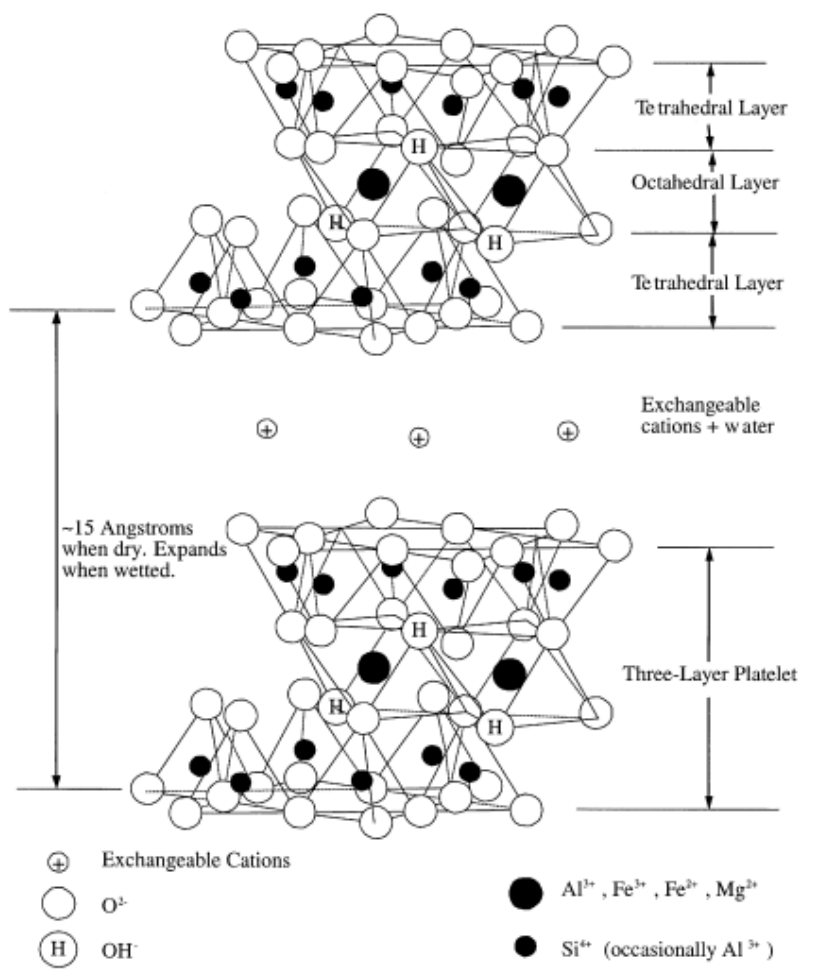

Fig. (2). Structure of the smectite crystal. Each clay platelet consists of three layers: two layers of silica tetrahedral and an octahedral alumina/magnesia layer joining them. Platelets are loosely bonded by counterions (typically sodium or calcium) between them. In the presence of water, the counter ions hydrate, causing the clay to expand [9].
Bentonite absorbs water and, hence, controls ball growth while imparting some plasticity to pellets. This property is important for handling of green pellets from a point to another during processes. Upon drying bentonite gives additional strength to pellets owing to dry film bonding of mineral grains.

The main disadvantage of bentonite and other binders based on silicate minerals is that they add silica to the finished pellet. Since the purpose of iron ore processing is, inter alia, to remove silicate minerals from the ore, adding silica back in the form of binder is counterproductive. This has prompted long-term interest in developing or discovering binders that contain no silica. Particular attention has been devoted to organic binders, which include a variety of carbon-based polymeric or fibrous compounds [9].

\subsection{Use of Organic Binders}

Many researchers investigated several alternative binders, mostly of organic polymer origin in order to reduce the acid gangue content of pellets. Some of the organic binders

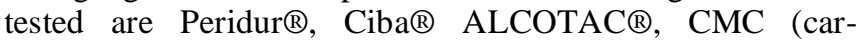
boxymethyl cellulose), starch (corn starch, potato starch, wheat flour), dextrin, glue, molasse etc. Most of the commercially available organic binders are derived from cellulose.

Kater and Steeghs [1] investigated the use of organic binders in iron ore pelletization using a high grade magnetite concentrate from Sweden with a Blaine number of 1910 $\mathrm{cm}^{2 /} / \mathrm{g}$ and size of $72.1 \%$ by weight minus $0.04 \mathrm{~mm}$. They comparatively tested Peridur vis-á-vis Wyoming bentonite. Their results showed that Peridur outperformed bentonite in terms of green pellet properties with reasonably satisfactory metallurgical properties.

Arol et al. [5] comparatively studied bentonite and selected organic binders namely Peridur CX3, Peridur C-10 and technical grade carboxymethyl cellulose (CMC) with magnetite concentrates from Divriği, Turkey. First two are commercial organic based binders manufactured by AkzoNobel and the latter is a cellulose derivative with carboxymethyl groups $(-\mathrm{CH} 2-\mathrm{COOH})$ bound to some of the hydroxyl groups of the glucopyranose monomers that make up the cellulose backbone. It was reported that organic binders are superior to bentonite in terms of drop numbers and wet compressive strength. The compressive strength of dried pellets at $400^{\circ} \mathrm{C}$ also found to be satisfactory. However, the compressive strength of pellets produced with organic binders and fired at $1200^{\circ} \mathrm{C}$ for 120 minutes were found insufficient (Fig. 3) as organic binders do not contribute to the strength of fired pellets.

The results of the physical and metallurgical properties of product pellets are summarized in Table 1. They have found that the compressive strength, before and after reduction, and tumbling resistance of product pellets produced with bentonite were notably higher than those produced with organic binders. Only bentonite binder was found to be satisfactory for industry when these physical properties are considered. However porosity and swelling of pellets produced with organic binders was larger than those of pellets produced with bentonite. As greater porosity is known to lead to faster re- 
duction, reducibility of pellets with organic binders was found to be greater than that of the bentonite pellets. In addition, one of the advantages of organic binders is that they do not contaminate the pellet composition since they burn out with no residue during thermal treatment. They also found that the Fe contents of pellets bonded with organic binders are slightly greater than those of pellets with bentonite as a natural consequence of adding no gangue.

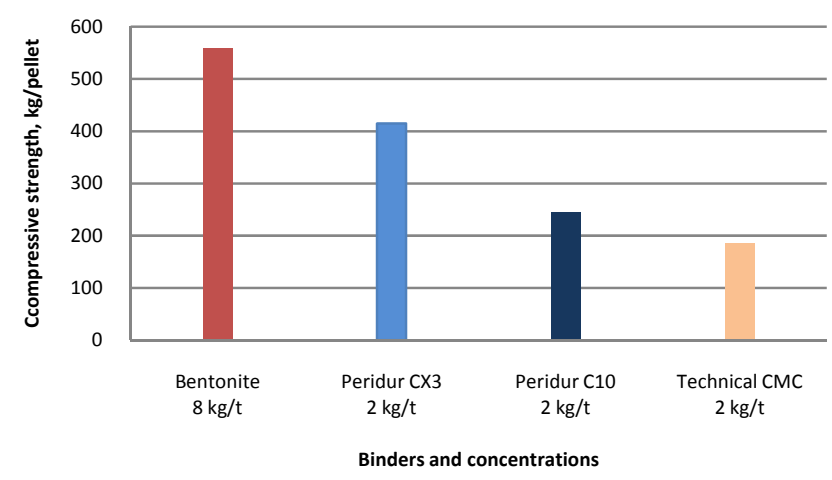

Fig. (3). Compressive strength of fired pellets $\left(1200^{\circ} \mathrm{C}, 120 \mathrm{~min}\right)$ produced with selected organic binders [5].

Sivrikaya and Arol $[7,12]$ investigated the use of organic binders in magnetite and hematite pelletizing. A high quality natural sodium bentonite from Tokat, Turkey was used as the reference binder. A magnetite concentrate from Divriği, Turkey with a Blaine number of $1617 \mathrm{~cm}^{2 /} / \mathrm{g}$ and size of $65.3 \%$ by weight minus $45 \mu \mathrm{m}$ and a hematite concentrate from Brazil with a Blaine number of $1890 \mathrm{~cm}^{2 /} / \mathrm{g}$ and size of $60 \%$ by weight minus $45 \mu \mathrm{m}$ were used. The magnetite ore analyzed $69.25 \% \mathrm{Fe}$ with $0.97 \% \mathrm{SiO}_{2}$ and hematite $66.62 \% \mathrm{Fe}$ with $5.71 \% \mathrm{SiO}_{2}$. Based on the previous studies, they focused on the pre-heated $\left(1000^{\circ} \mathrm{C}\right)$ and fired $\left(1300^{\circ} \mathrm{C}\right)$ pellet strength. It was reported that no organic binders alone can match the performance of bentonite in obtaining enough preheated strength of either magnetite (Fig. 4) or hematite (Fig. 5) pellets. The compressive strength of magnetite pellets produced with bentonite and organic binders were considerable higher than those of hematite pellets, as it is a well known fact that magnetite oxidizes to hematite during induration. Bridges, through recrystallization, formed during the oxidation of magnetite to hematite are widely believed to increase the pellet strength [8].

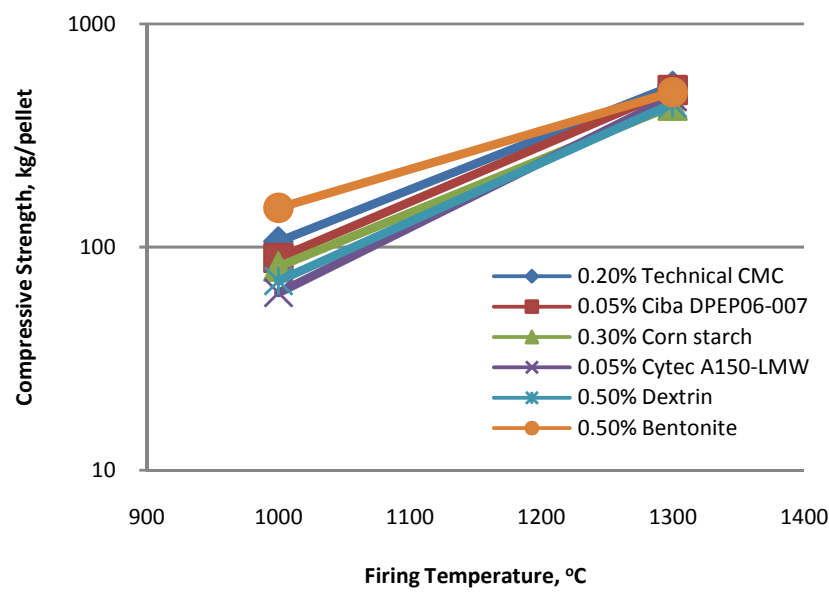

Fig. (4). The compressive strengths of magnetite pellets produced with selected organic binders [7].

Compressive strengths of pre-heated and fired hematite pellets produced with all organic binders were found to be much lower when compared to the values obtained with bentonite (Fig. 5). The organic binders burn out with virtually no residue at relatively low temperatures and they cannot provide any bonds between ore grains in the pellet structure. During the hematite pellet induration, the strength increase is only achieved -in contrast to magnetite pelletsthrough crystal growth and recrystallization. This growth can only be measured at temperatures of above $1200^{\circ} \mathrm{C}$. Up to this temperature; the individual ore grains and the pellet structure maintain the original shape. Only at higher temperatures of $1300^{\circ} \mathrm{C}$ the small ore particles form the first crystal bridges and recrystallization can be observed at $1350^{\circ} \mathrm{C}$. The presence of fine-grained particles is important for crystal growth that gives pellets the strength. At temperature above $1350^{\circ} \mathrm{C}$ hematite starts to dissociate into magnetite and oxygen, resulting in a weakening of pellet strength [8].

In all studies carried out on this subject, the results showed that organic binders were found to give good quality for green and dry pellets. However, they fail to impart enough strength to the pre-heated and fired pellets as a result of reduced slag bonding [1, 3-7]. This shortcoming of organic binders is the main disadvantage because a certain minimum compressive strength is necessary so that the pellets can survive the process steps after preheating, product handling, transportation, and handling by the end user [8].

Table 1. Physical and Metallurgical Properties of Product Pellets Produced with Selected Organic Binders [5]

\begin{tabular}{|c|c|c|c|c|c|c|c|}
\hline \multirow{2}{*}{$\begin{array}{l}\text { Binder } \\
\text { and } \\
\text { Addition Level }\end{array}$} & \multirow{2}{*}{$\begin{array}{c}\text { Compressive } \\
\text { Strength }^{(1)} \\
\text { kg/pellet }\end{array}$} & \multirow{2}{*}{$\begin{array}{c}\text { Compressive } \\
\text { Strength }^{(2)} \\
\text { kg/pellet }\end{array}$} & \multicolumn{2}{|c|}{ Tumbling Test } & \multirow{2}{*}{$\begin{array}{c}\text { Porosity } \\
\%\end{array}$} & \multirow{2}{*}{$\begin{array}{c}\text { Reducibility } \\
\text { ISO } 7215 \\
\%\end{array}$} & \multirow{2}{*}{$\begin{array}{c}\text { Swelling } \\
\%\end{array}$} \\
\hline & & & $\begin{array}{c}\text { TI } \\
+6.3 \mathrm{~mm}\end{array}$ & $\begin{array}{c}\text { AI } \\
-0.5 \mathrm{~mm}\end{array}$ & & & \\
\hline Bentonite $8 \mathrm{~kg} / \mathrm{t}$ & 560 & 68 & 94.5 & 5.3 & 15 & 65 & 8 \\
\hline Peridur CX3 $2 \mathrm{~kg} / \mathrm{t}$ & 415 & 43 & 88.0 & 10.2 & 22 & 65 & 8 \\
\hline Technical CMC 2 kg/t & 185 & 8 & 76.9 & 19.6 & 34 & 70 & 12 \\
\hline
\end{tabular}

${ }^{(1)}$ Compressive strength before reduction test

${ }^{(2)}$ Compressive strength after reduction test 


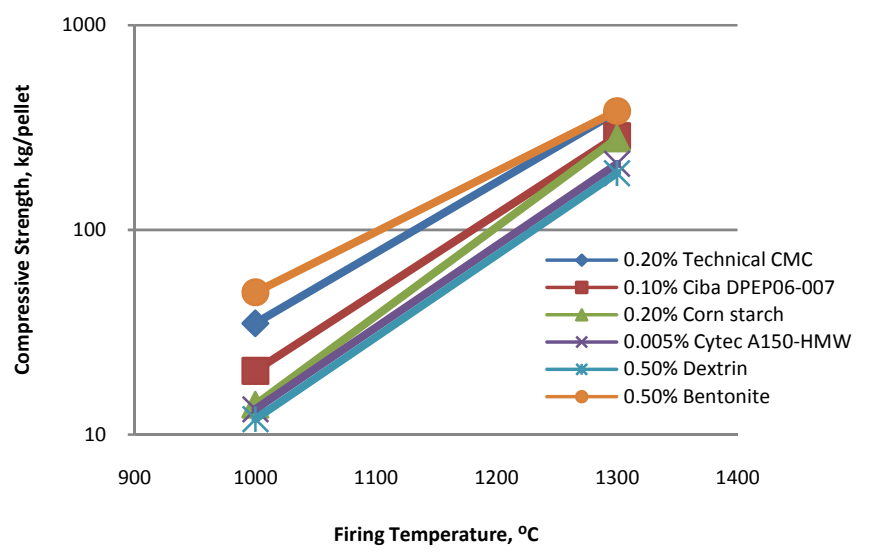

Fig. (5). The compressive strengths of hematite pellets produced with selected organic binders [12].

Pre-heated pellet strength is particularly important in the grate-kiln-cooler pellet induration system. If the pre-heated compressive strength of pellets is insufficient, pellets will be disintegrated on the travelling grate and in the rotary kiln. As a result process equipment and refractory will be damaged by the pellet dust formed and carried in gas streams. If the problem is not rectified within a reasonable span of time, plant operation may be interrupted and the efficiency in terms of productivity and quality will decrease.

The fired pellets with low strength give rise to losses as a result of the production, unwanted fines or dust during process, storage and transport. In addition, fines also cause operational difficulties in reduction furnaces. Therefore, organic binders have not found widespread application in the industry.

\subsection{Use of Boron Compounds}

It appears that although organic binders hold some promises for iron ore pelletization, they still fail to satisfy all the requirements especially those related to the strength of preheated and indurated pellets. In order to use organic binders successfully, this shortcoming must be overcome. One plausible method is to introduce a slag forming constituent to the pellet mix so that the strength of the pellets would be reinstated as a result of slag bonds.

Boron compounds may be the potential additive to organic binders as they are known to lower the melting point of silica glasses. Numerous boron compounds of natural or synthetic origin can be used for this purpose. Some of the boron compounds tested as binder or additive in iron ore pelletizing are; colemanite, tincal, borax pentahydrate and boric acid.

Colemanite or calcium-borate salt is a natural boron mineral found in evaporate deposits of alkaline lacustrine environments. It is a secondary mineral that forms by alteration of borax and ulexite. Colemanite has a chemical formula $2 \mathrm{CaO}_{3} \mathrm{~B}_{2} \mathrm{O}_{3} \cdot 5 \mathrm{H}_{2} \mathrm{O}$ and melting point of $986^{\circ} \mathrm{C}$ [13]. The average chemical components of colemanite are $43 \% \quad \mathrm{~B}_{2} \mathrm{O}_{3}$, $26 \% \mathrm{CaO}, 6.50 \% \mathrm{SiO}_{2}$ and $0.50 \% \mathrm{SO}_{3}$.

Tincal or sodium-borate is a natural boron mineral known as borax decahydrate and a chemical formula $\mathrm{Na}_{2} \mathrm{O} \cdot 2 \mathrm{~B}_{2} \mathrm{O}_{3}$. $10 \mathrm{H}_{2} \mathrm{O}$. The $\mathrm{B}_{2} \mathrm{O}_{3}$ content is $36.47 \%$ and melting point of borax decahydrate is $62^{\circ} \mathrm{C}$ when heated in closed atmosphere [14].

Borax pentahydrate $\left(\mathrm{Na}_{2} \mathrm{~B}_{4} \mathrm{O}_{7} .5 \mathrm{H}_{2} \mathrm{O}\right)$ is a sodium-borate derivative with $48 \% \mathrm{~B}_{2} \mathrm{O}_{3}$ and $21.37 \% \mathrm{Na}_{2} \mathrm{O}$ has a melting point of $200^{\circ} \mathrm{C}$ when heated in closed atmosphere [15].

Boric acid has the chemical formula $\mathrm{H}_{3} \mathrm{BO}_{3}$, alternatively written $\mathrm{B}(\mathrm{OH})_{3}$. Boric acid is soluble in boiling water. When heated above $170^{\circ} \mathrm{C}$, it dehydrates, forming metaboric acid $\mathrm{HBO}_{2}$. Metaboric acid is a white, cubic crystalline solid and is only slightly soluble in water. Boric acid melts at about $236^{\circ} \mathrm{C}$.

None of those boron compounds contain significant $\mathrm{SiO}_{2}$ or $\mathrm{Al}_{2} \mathrm{O}_{3}$ which are unwanted impurities in iron pellet composition.

The iron ores or concentrates contain varying amounts of $\mathrm{SiO}_{2}$. On the other hand, the boron compounds have significant amount of boron in their compositions. Their presence in the pellet mix leads to formation of borosilicate glasses. Borosilicate glasses are known for their low melting temperature. Thus, formation of borosilicate glasses is expected to take place at lower temperatures. This occurrence would contribute to the strength of the pellets through slag bonding [8]. Absence of acidic impurities in boron compounds combined with low melting temperature, good thermal and mechanical properties of borosilicate glasses favor the use of boron compounds as slag forming constituents. When used with an organic binder, while the boron compounds render the required properties to pre-heated and fired pellets, green and dry pellets attain the required quality through organic binders. Hence, the two together can be used as binder in place of bentonite in iron ore pelletization [7].

Boron compounds have been tested as a binder in iron ore pelletization either alone or in combination with organic binders.

In one of the studies, calcined colemanite alone and combination with bentonite were tested as alternative binder in the pelletizing of magnetite concentrate with $64.70 \% \mathrm{Fe}$ and $4.22 \% \mathrm{SiO}_{2}$ [16]. The addition level of binders, firing temperature and particle size of iron ore were investigated as operation parameters of pellets. Bentonite and calcined colemanite addition levels were in the range of $0.5,1.0,1.5$, $2.0 \%$ and $1,2,3,4,5,6,7 \%$, respectively. The wet and dry compressive strengths indicate that, the calcined colemanite as a binder is insufficient with regard to wet and dry pellet quality, as seen in Fig. (6). It was reported that increasing firing temperature from $1200^{\circ} \mathrm{C}$ to $1350^{\circ} \mathrm{C}$ increases the compressive strength of the pellets produced with bentonite and calcined colemanite. It was also reported that increasing concentration of calcined colemanite from $1 \%$ to $7 \%$ increases the compressive strength pellets significantly (Fig. 7). In order to obtain pellets with both sufficient wet and indurated strength, combination of bentonite and calcined colemanite were tested, and meaningful increases in compressive strength of fired pellets were obtained (Fig. 8).

Timuçin et al. [17] investigated the reducibility properties of pellets produced with colemanite addition. They used itabarite ore which is $99.66 \% \mathrm{Fe}_{2} \mathrm{O}_{3}$. The ore used in the pelletizing experiments was ground to $70.90 \%$ passing $37 \mu \mathrm{m}$. Different percentages of calcined colemanite were added to 
the iron ore before pelletizing and the pellets with $10 \mathrm{~mm}$ diameter were fired at $800^{\circ} \mathrm{C}$. The fired pellets then were reduced in a tube furnace at $900^{\circ} \mathrm{C}$ under $\mathrm{CO}$ atmosphere and reducibility of pellets was calculated. The results showed that calcined colemanite addition has a catalytic effect on the reducibility of colemanite added pellets. It was reported that, while the reducibility of pellets with no binder was only $92 \%$ after 4 hours, the reducibility of $0.6 \%$ colemanite added pellets was found to be completely reduced in 2 hours, as seen in Fig. (9). The maximum catalytic effect of calcined colemanite was at $0.6 \%$, the greater addition levels decrease the catalytic effect of colemanite.

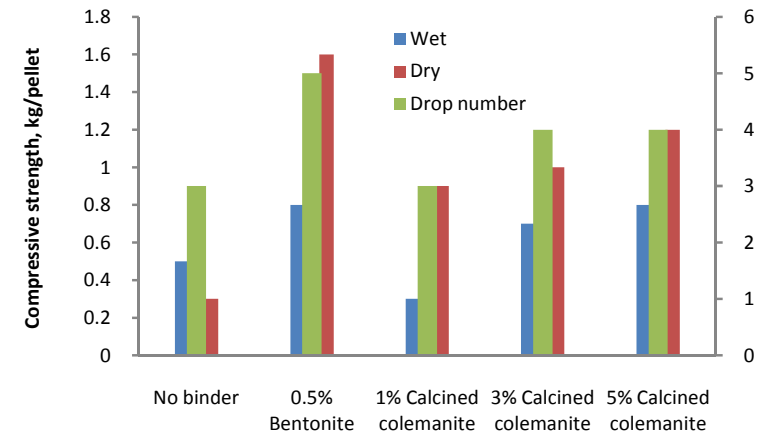

Binders and concentrations

Fig. (6). Compressive strengths of wet and dry pellets and drop numbers of wet pellets [16].

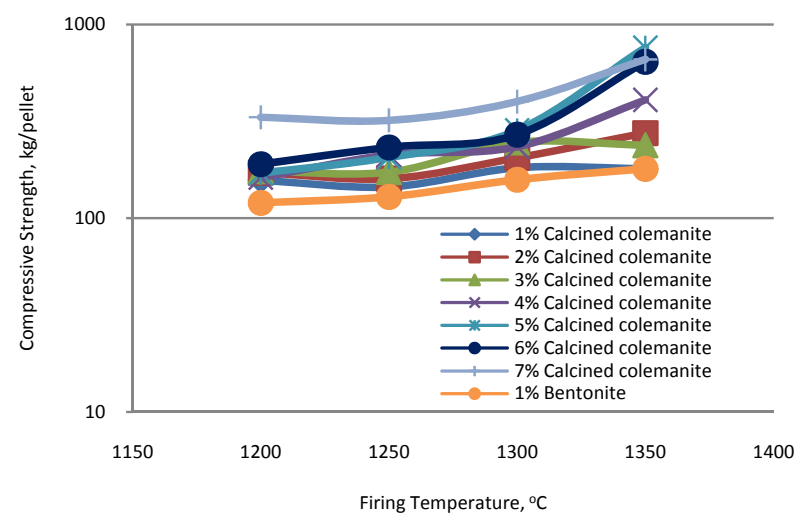

Fig. (7). Effect of calcined colemanite addition level on the compressive strength of fired magnetite pellets made using -200 mesh particle size [16].

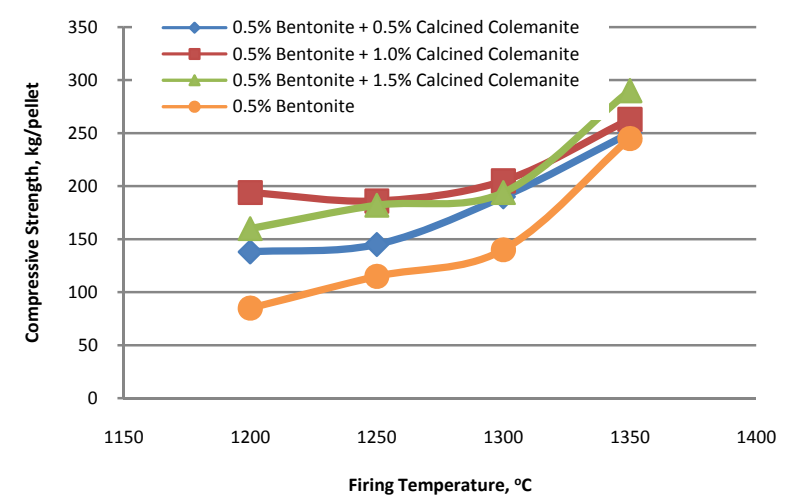

Fig. (8). Effect of bentonite and calcined colemanite addition on the compressive strength of magnetite pellets made using -200 mesh particle size [16].
The effect of colemanite and bentonite combination on the reducibility of pellets was also investigated in the same study. It was reported that the catalytic effect of colemanite on reducibility of iron ore pellets was decreased when used together with bentonite Fig. (10).

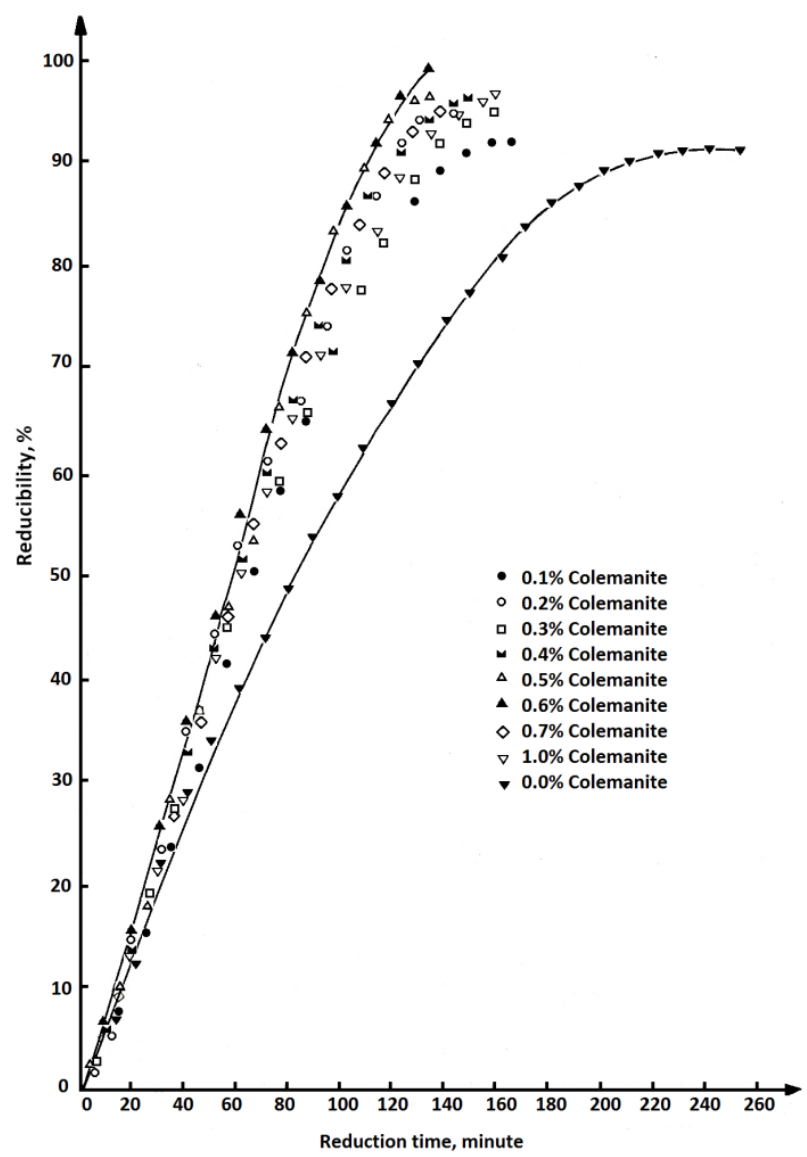

Fig. (9). The effect of calcined colemanite addition on the reducibility of itabarite pellets [17].

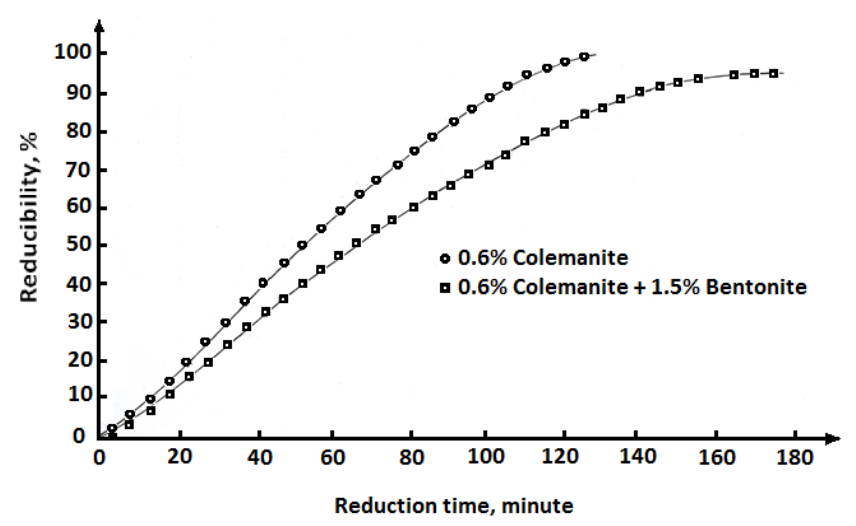

Fig. (10). The effect of calcined colemanite and bentonite addition on the reducibility of itabarite pellets [17].

Sivrikaya and Arol [18] investigated the boron compounds, namely colemanite, tincal, borax pentahydrate and boric acid as additives in iron ore pelletization. Based on the previous studies $[5,6]$, they focused on the pre-heated $\left(1000^{\circ} \mathrm{C}\right)$ and fired $\left(1300^{\circ} \mathrm{C}\right)$ pellet strength. The boron compounds were tested alone and in combination with organic binders; technical grade CMC, corn starch, Ciba DPEP06- 
0007, Cytec A150-LMW, Cytec A150-HMW and dextrin. In this study, colemanite was used after calcination at $550^{\circ} \mathrm{C}$ to remove the chemically bonded water. Other additives were used as powder or solution in distilled water. Magnetite and hematite pellets with selected organic binders and boron compounds were produced. The drop numbers and moisture content of magnetite and hematite pellets are given in Fig. (11) and Fig. (12), respectively. The drop number was found to be 3 for magnetite pellets and 3.4 for hematite pellets bonded with $0.50 \%$ bentonite which is established as the reference level. The drop numbers of pellets bonded with organic binders found to be sufficient when compared to bentonite. However, the drop numbers of both magnetite and hematite pellets produced with only boron compounds were found to be smaller than the reference level. Because they contribute no strength in wet pellets due to lack of water adsorption capacity, adhesional and cohesional forces. Therefore the use of only boron compounds as binder is insufficient for desired wet pellet quality in both magnetite and hematite pellets. However, the drop numbers of pellets bonded with the combination of an organic binder and a boron compound were found to be acceptable.

The effect of addition level of calcined colemanite on the compressive strength of pre-heated and fired magnetite and hematite pellets was also investigated in the same studies [7, 12]. It was reported that increasing concentration of calcined colemanite from $0.25 \%$ to $1.00 \%$ increases the pre-heated and fired pellet compressive strengths in both magnetite and hematite pellets. Results showed that the magnetite pellets produced with all the addition levels of calcined colemanite, except $0.25 \%$, had compressive strengths equal or better than the magnetite pellets produced with $0.50 \%$ bentonite (Fig. 13). The contribution of calcined colemanite on the compressive strengths of hematite pellets is more pronounced than those on magnetite pellets. All the compressive strengths of hematite pellets produced with calcined colemanite were found to be much greater than those of pellets produced with bentonite (Fig. 14). These findings are expected as the oxidation of magnetite to hematite at lower temperatures is one of the major binding mechanisms, while hematite acquires a lesser strength through crystal growth and recrystallization [8].

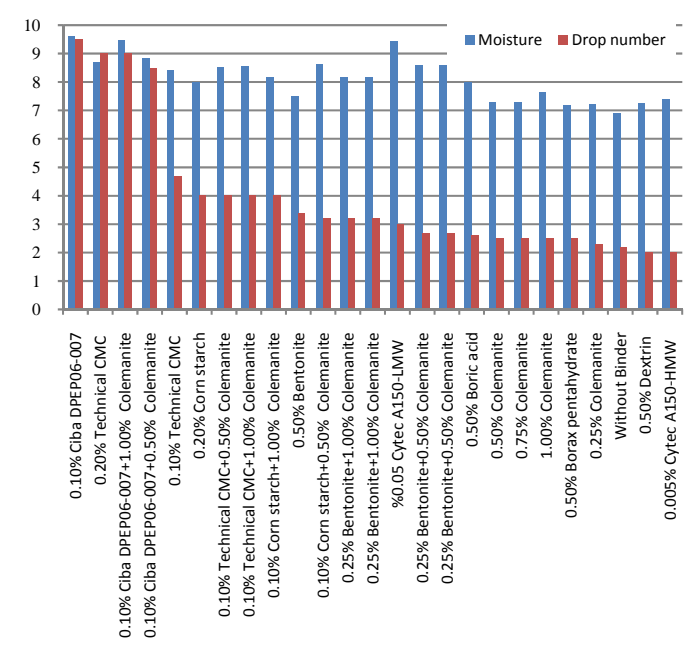

Fig. (12). The drop numbers and moisture contents of hematite pellets produced with different binders [18].

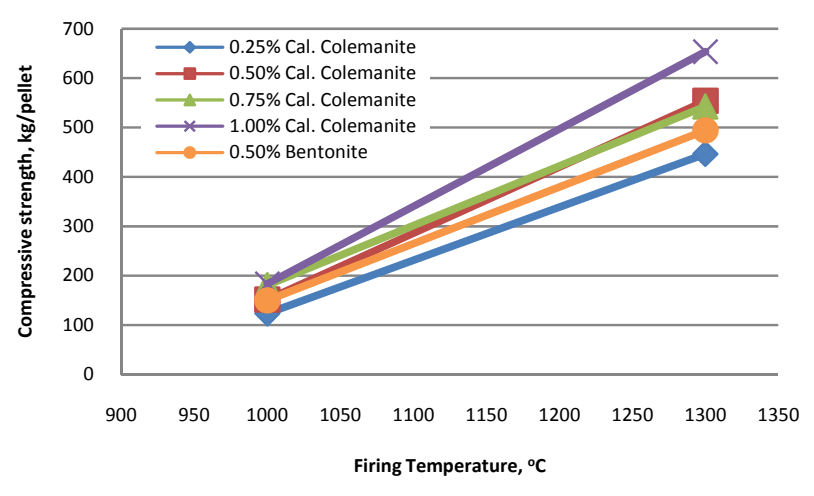

Fig. (13). Compressive strength of pre-heated and fired magnetite pellets produced with calcined colemanite [7].

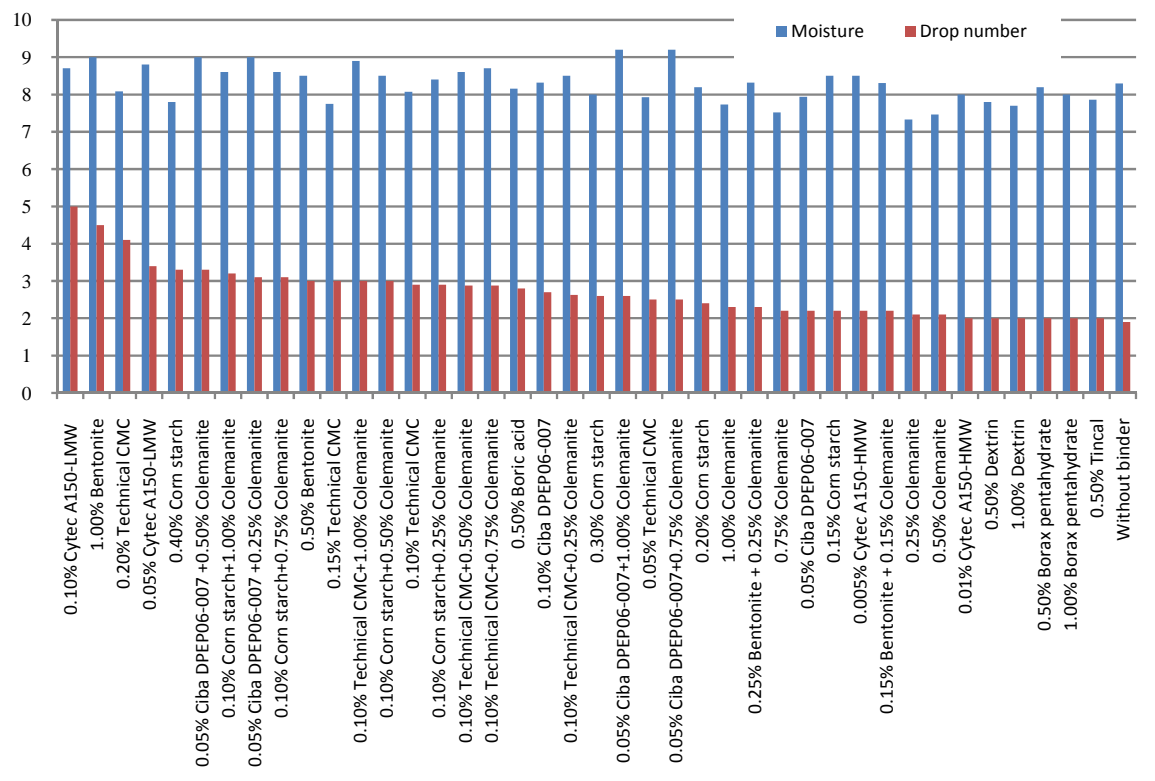

Fig. (11). The drop numbers and moisture contents of magnetite pellets produced with different binders [18]. 
Besides colemanite, other boron compounds such as tincal, boraxpentahydrate and boric acid were also tested as binder by the same researchers [7, 12]. When the compressive strength of pre-heated magnetite pellets are considered, it can clearly be seen from Fig. (15) that only calcined colemanite added pellets had compressive strengths comparable to those of pellets bonded with bentonite. The compressive strengths of pellets produced with other boron compounds (tincal, boraxpentahydrate and boric acid) found to be smaller than those of pellets produced with bentonite.

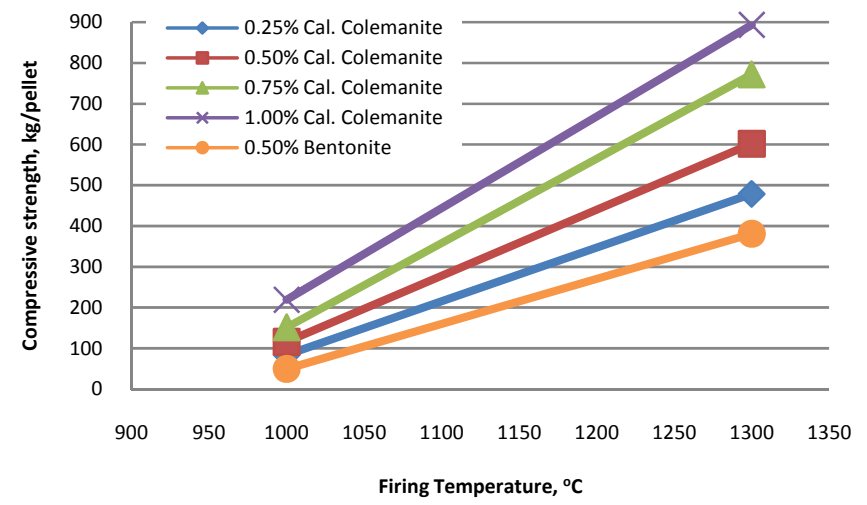

Fig. (14). Compressive strength of pre-heated and fired hematite pellets produced with calcined colemanite [12].

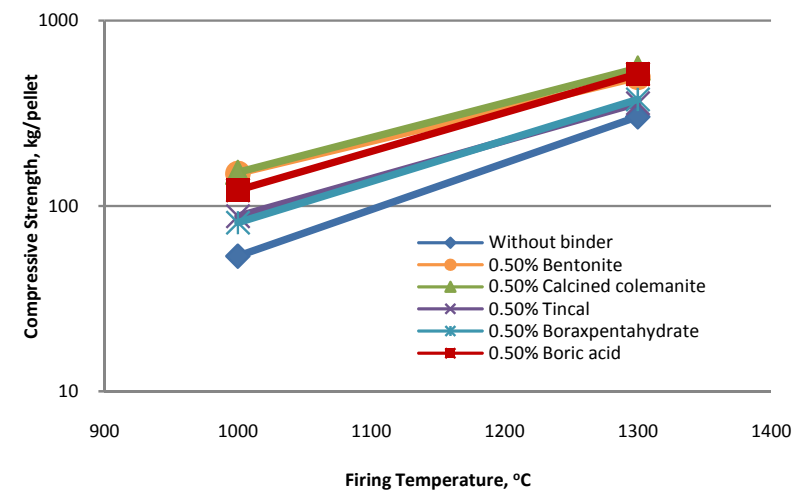

Fig. (15). Compressive strength of magnetite pellets produced with different boron compounds [7].

In hematite pellets, the contribution of all the boron compounds to the compressive strength of pre-heated pellets was significantly greater than pellets produced with bentonite, as shown in Fig. (16). The compressive strengths of pre-heated pellets produced with all the boron compounds had nearly twice the compressive strength of the pellets bonded with bentonite.

In view of the fact that organic binders render acceptable qualities to the green pellets [18] and calcined colemanite improve the pre-heated and fired pellet strength [7, 12], they were used together to produce magnetite and hematite pellets [18]. The results for different organic binder-colemanite combination are given in Fig. (17) for magnetite pellets and in Fig. (18) for hematite pellets. As seen, while organic binder-colemanite combination yielded pellets with nearly equal compressive strengths when magnetite were used Fig. (17), the compressive strengths of pre-heated and fired pellets of hematite were notably greater, Fig. (18).

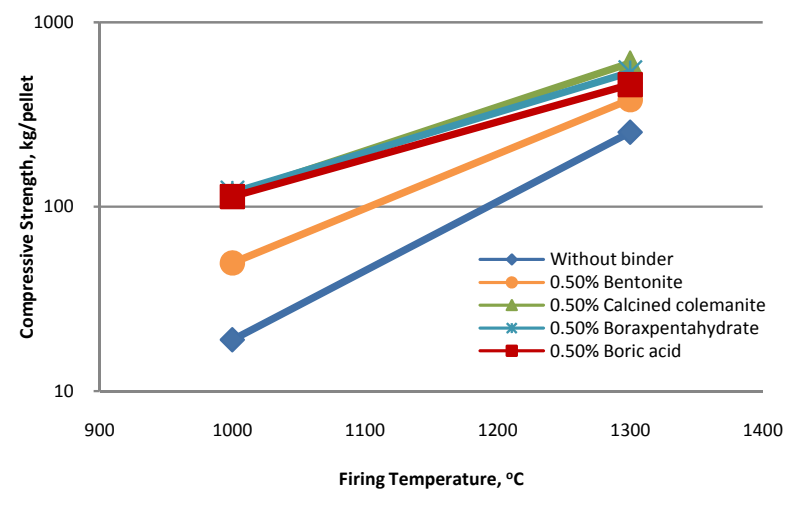

Fig. (16). Compressive strength of hematite pellets produced with different boron compounds [12].

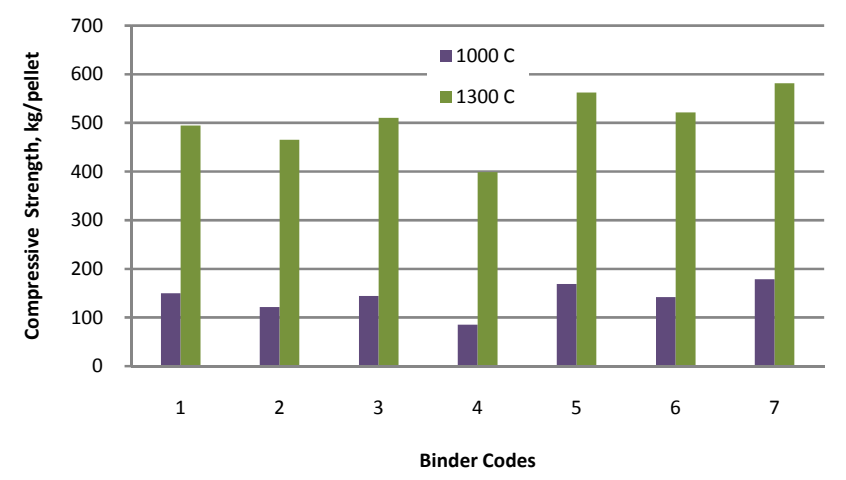

Fig. (17). Compressive strength of magnetite pellets produced with organic binder-colemanite combinations [18].

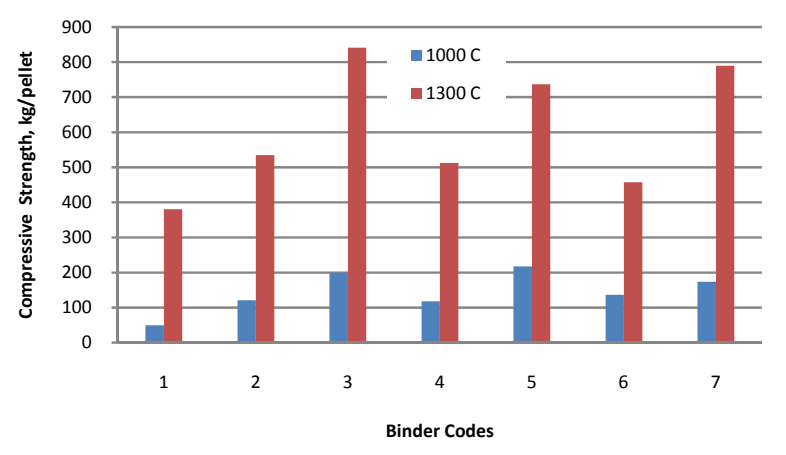

Fig. (18). Compressive strength of hematite pellets produced with organic binder-colemanite combinations [18].

Organic binder-colemanite combinations are shown by codes in Figs. (17 and 18);

$1: 0.50 \%$ Bentonite (reference binder)

$2: 0.10 \%$ Technical CMC $+0.50 \%$ Calcined colemanite

$3: 0.10 \%$ Technical CMC $+1.00 \%$ Calcined colemanite

$4: 0.05 \%$ Ciba DPEP06-007 + 0.50\% Calcined colemanite

$5: 0.05 \%$ Ciba DPEP06-007 + 1.00\% Calcined colemanite

$6: 0.10 \%$ Corn starch $+0.50 \%$ Calcined colemanite

$7: 0.10 \%$ Corn starch $+1.00 \%$ Calcined colemanite

Sivrikaya [19] carried out some preliminary tests to use calcined colemanite together with bentonite in order to either 
lower bentonite consumption level or induration temperature. The results of the tests for hematite pellets are given in Fig. (19). As can be seen, it was possible to obtain equal compressive strength with lower bentonite addition level to hematite pellets when colemanite was also used at $0.50 \%$ and $1.00 \%$, Fig. (19).

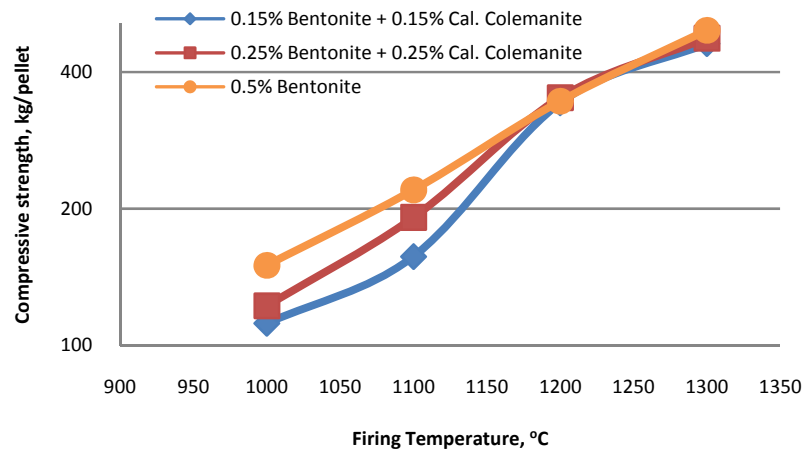

Fig. (19). Compressive strength of hematite pellets produced with bentonite-colemanite combinations [19].

In order to delineate the bonding mechanism in magnetite and hematite pellets, Sivrikaya [19] investigated the crystal change and crystal growth of indurated pellets. During heating under oxidizing atmosphere, the magnetite oxidizes to hematite with simultaneous conversion of the cubic magnetite into the hexagonal hematite lattice. According to the genesis of magnetite, the oxidation starts at about $300-$ $600^{\circ} \mathrm{C}$ and is to be terminated at a temperature of $1100^{\circ} \mathrm{C}$. It begins on the crystal and grain surfaces [11]. This is confirmed on the magnetite pellets, fired at $1300^{\circ} \mathrm{C}$, produced with $0.50 \%$ bentonite and $0.50 \%$ calcined colemanite. The crystal growth is better in bentonite bonded magnetite pellet than colemanite bonded magnetite pellet, Figs. (20) and (21). However, the crystal growth is better in hematite pellets produced with calcined colemanite than those of hematite pellets bonded with bentonite, Figs. (22) and (23). These findings can explain the greater strength of hematite pellets obtained upon colemanite addition, as larger crystals lead to stronger pellets.

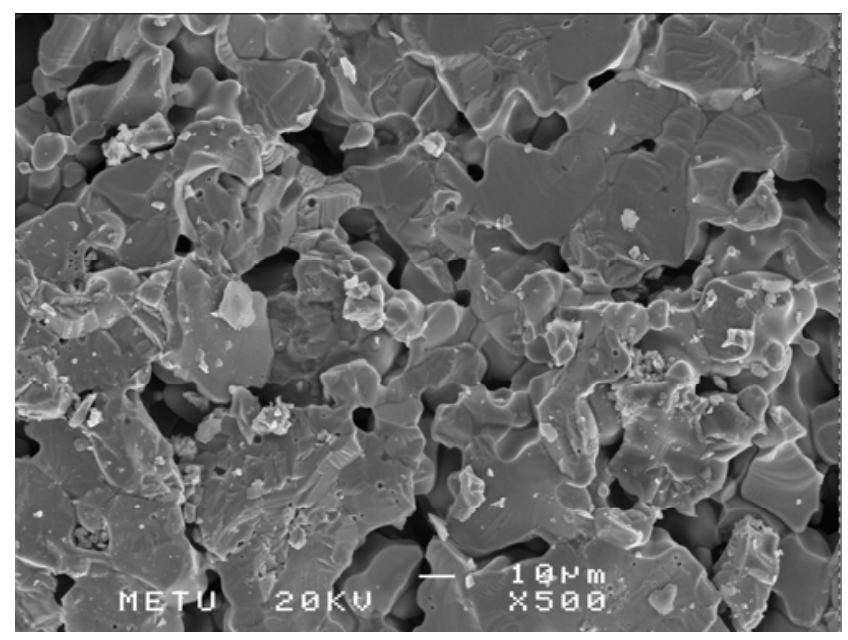

Fig. (20). Fired magnetite pellets with $0.50 \%$.

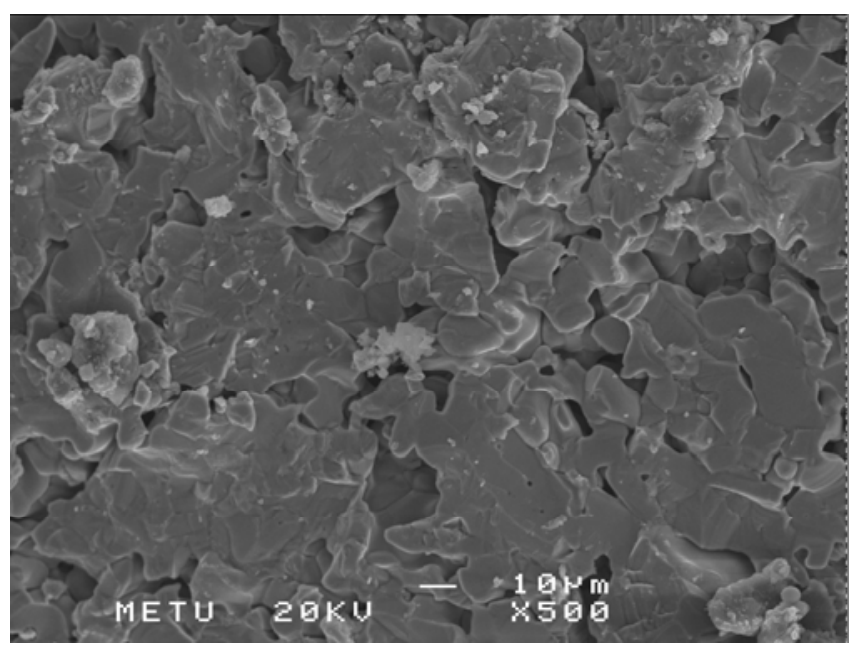

Fig. (21). Fired magnetite pellets with $0.50 \%$ calcined bentonite and colemanite [19].

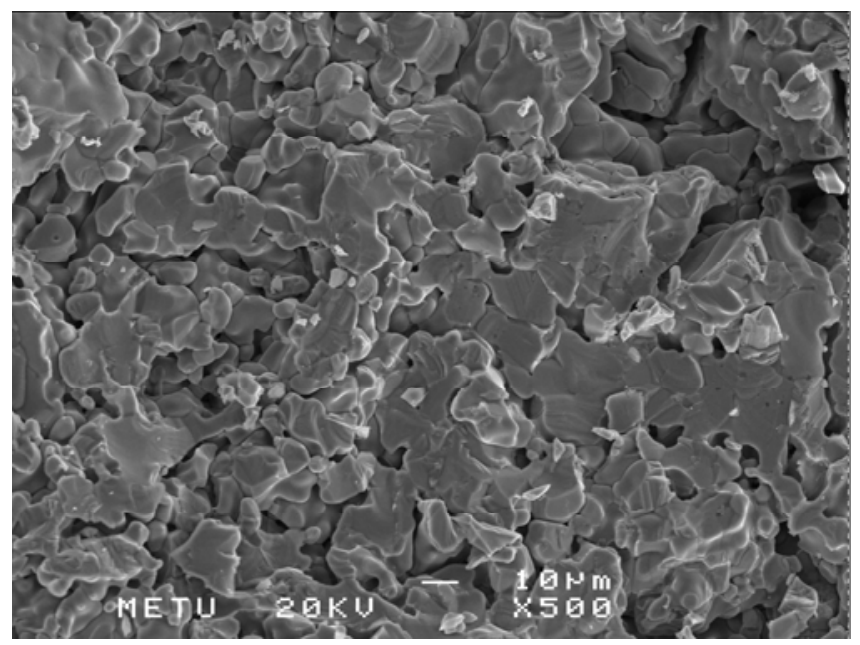

Fig. (22). Fired hematite pellets with $0.50 \%$.

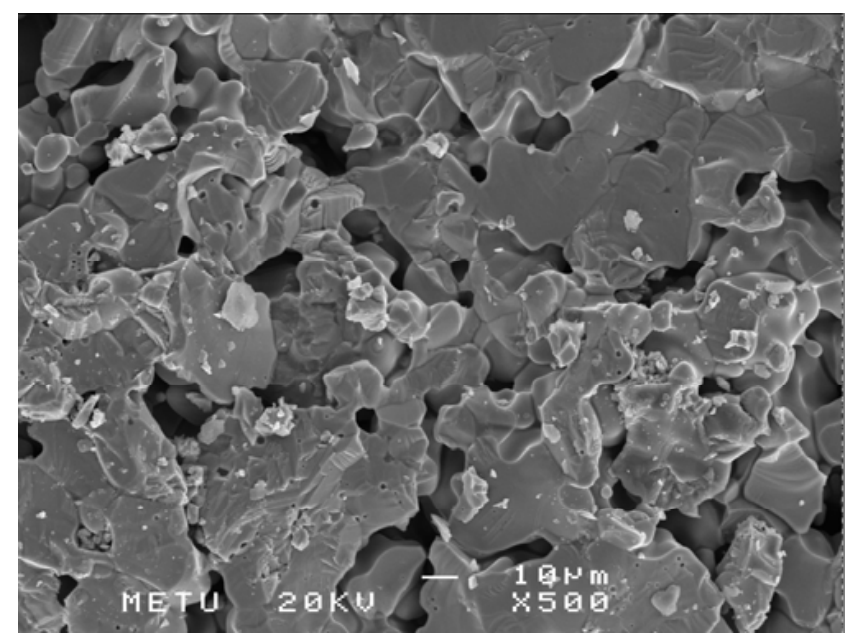

Fig. (23). Fired hematite pellets with $0.50 \%$ calcined bentonite and colemanite [19].

Sivrikaya [19] also investigated the minerology of the magnetite pellets. The base X-ray diffractogram was deter- 


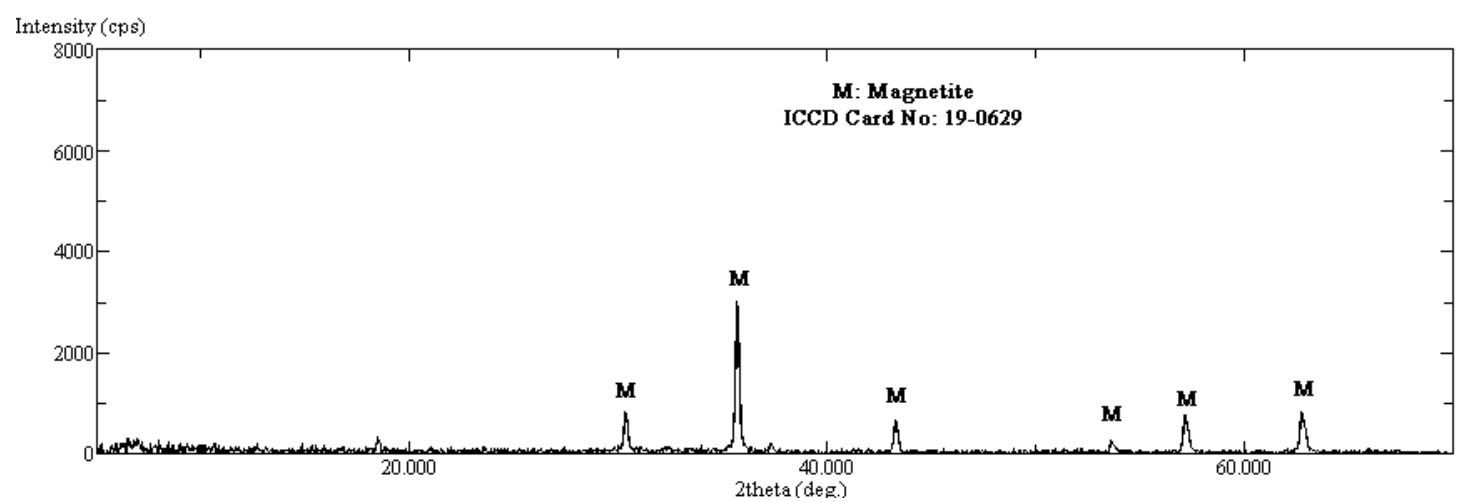

Fig. (24). X-ray diffractogram of magnetite concentrate dried at $100{ }^{\circ} \mathrm{C}[19]$.

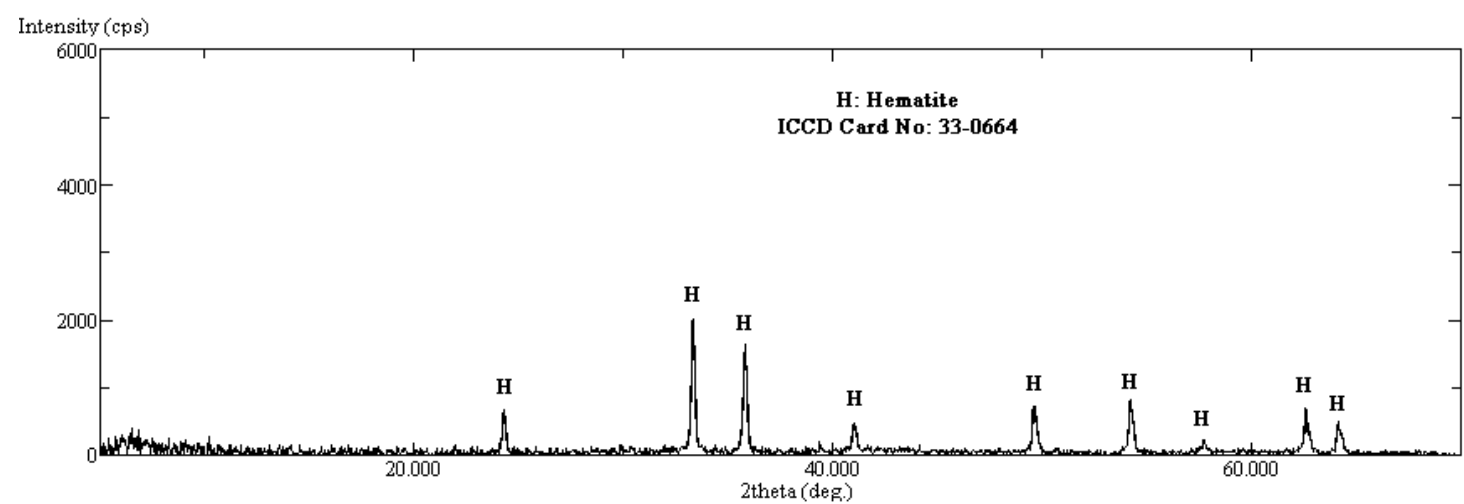

Fig. (25). X-ray diffractogram of magnetite pellets bonded with $0.50 \%$ bentonite and fired at $1300{ }^{\circ} \mathrm{C}[19]$.

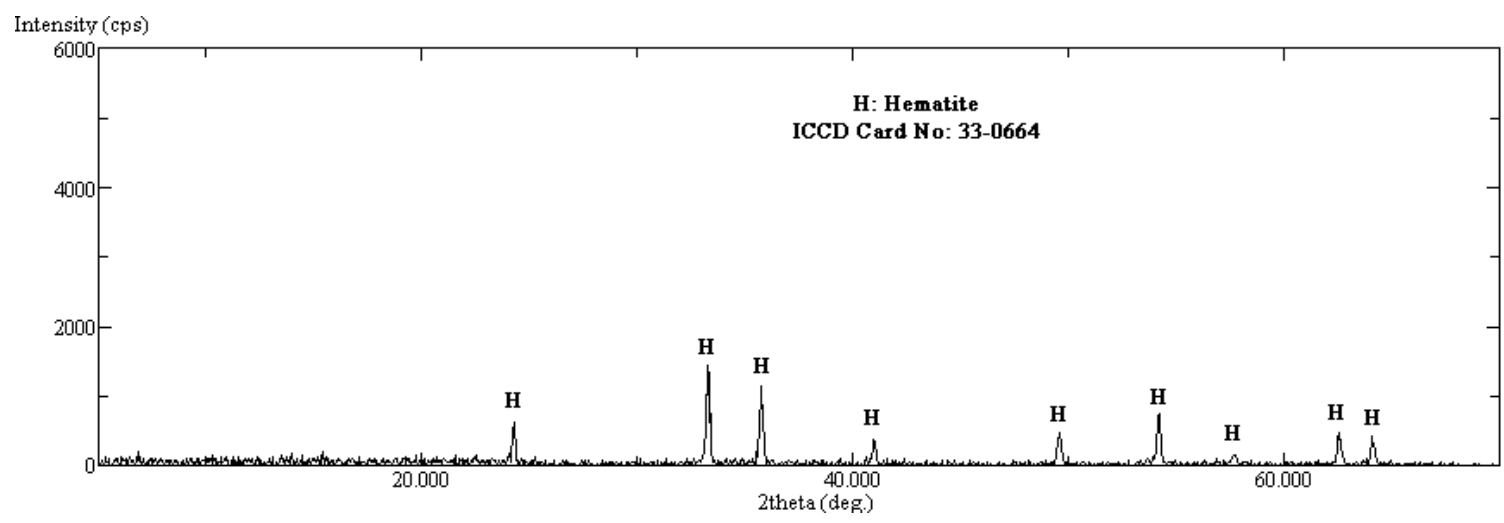

Fig. (26). X-ray diffractogram of magnetite pellets bonded with $0.50 \%$ calcined colemanite and fired at $1300{ }^{\circ} \mathrm{C}$ [19].

mined with dry magnetite concentrate and given in Fig. (24) show that magnetite is the only constituent. The $\mathrm{X}$-ray diffractograms of magnetite pellets produced with bentonite binder (Fig. 25) and calcined colemanite additive (Fig. 26) indicated that hematite is the main constituent. The XRD analyses of magnetite pellets showed no new compounds. As the addition levels of bentonite and calcined colemanite were very low $(0.5 \%)$, their differential peaks can not be detected by XRD. These findings well confirm with earlier reports.

\section{CONCLUSIONS}

- Bentonite is the most preferred binder industrially but has some disadvantage due to its $\mathrm{SiO}_{2}$ and $\mathrm{Al}_{2} \mathrm{O}_{3}$ contents which are unwanted impurities in pellet composition.
- Organic binders have been suggested as alternative binders to bentonite. The results have shown that organic binders render good quality to green and dry pellets, they have failed in terms of pre-heated and fired pellet strength.

- Boron compounds have been considered as a slag forming constituent which contribute to strength of pre-heated and fired pellets through slag bonds formed at comparatively low temperatures.

- Organic binders and boron compounds can be used together to compensate the shortcoming of either material. Sufficient wet strength, pre-heated and fired compressive strengths were obtained with the use of combination of 
an organic binder and boron compounds when compared to the pellets produced with conventional bentonite binder.

- The use of combination of an organic binder and a boron compound as an alternative to bentonite in iron ore pelletization can be beneficial in terms of

(a) reducing the acidic impurity constituents introduced by bentonite,

(b) reducing the firing temperatures in pelletization of hematite ores leading a lower energy consumption.

- Calcined colemanite may improve the reducibility of pellet.

\section{REFERENCES}

[1] T. Kater, and H.R.G. Steeghs, "Organic binders for iron ore pelletization", In: 57th Annual Meeting of the Minnesota Section of AIME, Duluth-MN, USA, 1984, pp.13.1-13.29.

[2] V.M. Chizhikova, R.M.,Vainshtein, S.N. Zorin, T.I. Zainetdinov, G.A. Zinyagin and A.A. Shevchenko, "Production of iron ore pellets with an organic binder," Metallurgist, vol.47, nos.3-4, pp.141-146, 2003

[3] R.P. de Souza, C.F. de Mendonca and T. Kater, "Production of acid iron ore pellet for direct reduction, using an organic binder," Mining Eng, vol. 36, no. 10, pp. 1437-1441,1984.

[4] H.E. Goetzman, R.L. Bleifuss and J. Engesser, "Investigation of carboxymethyl cellulose binders for taconite pelletizing," In: SME Annual Meeting, Phoenix, AZ, USA, 1988, pp. 88-111.

[5] A.I. Arol, G. Özbayoğlu, C. Hiçyllmaz, Ü. Akdemir and M. Mamurekli, "Determination of an alternative binder to bentonite in iron ore pelletization," In: 11th.Turkey Mining Scientific and Technical Congress, 1989, pp. 393-405.
[6] A.I., Arol, "The use of organic binders in iron pelletization," Unpublished study, 1997.

[7] O. Sivrikaya and A.I. Arol, "Use of colemanite as an additive in iron ore pelletizing", In: 11th International Mineral Processing Symposium, Antalya, Turkey, 2008, pp.1121-1127.

[8] K. Meyer, Pelletizing of Iron Ores. Springer-Verlag Berlin Heidelberg: New York, 1980

[9] T.C. Eisele and S.K. Kawatra, "A review of binders in iron ore pelletization", Miner. Process. Extr. Metall., vol. 24, pp. 1-90, 2003 .

[10] S.K. Kawatra and S.J. Ripke, "Pelletizing steel mill desulfurization slag", Int. J. Miner. Process., vol. 65, pp. 165-175, 2002.

[11] D.F. Ball, J. Dartnell, J. Davison, A. Grieve and R. Wild, Agglomeration of Iron Ores. American Elsevier Publishing Company, Inc.: New York, 1973.

[12] O. Sivrikaya and A.I. Arol, "Use of organic binders and borates in hematite pelletization," In: 13th Balkan Mineral Processing Congress, Bucharest, Romania, 2009, pp. 337-341.

[13] E. Tektas, "Bigadiç ground colemanite health and safety data sheet", Eti Holding A.S. Research \& Development Department, Turkey 2003.

[14] A, Mergen, E. Tektas, "Borax decahydrate health and safety data sheet", Eti Holding A.S. Research \& Development Department, Turkey 2003.

[15] E. Tektas, T.T. Aydın and S. Cüce., "Etibor-48 (borax pentahydrate) health and safety data sheet", Eti Holding A.Ş. Research \& Development Department, Turkey 2007.

[16] M.N. Köroğlu, "Use of calcined colemanite and bentonite as binders in the pelletizing of Hasan Celebi iron ore", M.S. thesis, Middle East Technical University, Ankara, Turkey, 1980.

[17] M. Timuçin, A. Geveci, N. Sevinç, Y. Topkaya and H. Eriç, "The use of colemanite in steel production", Middle East Technical University Project No:84-04-07-00-13, pp. 100-111, 1986.

[18] O. Sivrikaya and A.I. Arol, "Use of organic binders and borates in pelletizing of iron oxides", In: 4th International Boron Symposium, Eskişehir, Turkey, 2009, pp. 251-256.

[19] O. Sivrikaya, Unpublished results of $\mathrm{PhD}$ thesis, Middle East Technical University, Ankara, Turkey, 2010.

(C) Sivrikaya and Arol; Licensee Bentham Open.

This is an open access article licensed under the terms of the Creative Commons Attribution Non-Commercial License (http://creativecommons.org/licenses/ by-nc/3.0/) which permits unrestricted, non-commercial use, distribution and reproduction in any medium, provided the work is properly cited. 